\title{
Programação em Blocos: impacto de um projeto de extensão executado em Escolas públicas de Diamantina/MG
}

\section{Block Programming: impact of an extension project carried out at public schools in Diamantina/MG}

\section{Riann Martinelli Batista}

Universidade Federal dos Vales do Jequitinhonha e Mucuri

\section{Alexandre Ramos Fonseca}

Universidade Federal dos Vales do Jequitinhonha e Mucuri

Euler Guimarães Horta

Universidade Federal dos Vales do Jequitinhonha e Mucuri

Resumo: O ensino da lógica de programação em escolas do Ensino Básico está consolidado em alguns países. No Brasil existem poucas iniciativas que facilitam o contato com esse conteúdo na escola. Um projeto de extensão universitária foi criado visando a oferecer o primeiro contato com a lógica de programação a alunos da rede pública. No projeto, alunos da cidade de Diamantina/MG tiveram contato com ferramentas lúdicas de programação em blocos e de criação de aplicativos móveis. O intuito foi apresentar a base estrutural de algoritmos utilizando blocos, permitindo aos participantes desenvolverem aplicativos. A partir de dados coletados por meio de observação e de respostas a questionários, foi possível fazer um levantamento dos impactos desse tipo de conteúdo para estudantes da Educação Básica. Apesar do alto índice de evasão e dificuldade de coleta dos questionários, os resultados foram positivos, destacando-se o aumento do interesse dos participantes em cursarem computação no futuro.

Palavras-chave: Lógica de Programação. Programação em Blocos. Ensino de Computação. Educação Básica. Escolas Públicas em Diamantina.

Abstract: Teaching of programming logic in elementary schools is well established in some countries. In Brazil there are few initiatives that facilitate the contact with this subject at school. A university extension project was created aiming to offer the first contact with the programming logic to public school students. In the project, students from the city of Diamantina/MG had contact with ludic block programming and mobile application tools. The aim was to present the structural basis of algorithms using blocks, allowing participants to develop their own applications. From data collected through observation and answers to questionnaires, it was possible to survey the impacts of this type of content applied to students of elementary schools. Despite the high rate of evasion and difficulty in collecting the questionnaires, the results were positive, highlighting the increased interest of participants in studying computing in the future.

Palavras-chave: Programming Logic. Block Programming. Computer teaching. Basic education. Public Schools in Diamantina. 
BATISTA, Riann Martinelli; FONSECA, Alexandre Ramos; HORTA, Euler Guimarães. Programação em Blocos: impacto de um projeto de extensão executado em Escolas públicas em Diamantina/MG. Informática na Educação, Porto Alegre, v. 23, n. 2, p. 87-103, maio./ago. 2020.

\section{Introdução}

Nos dias de hoje, os jovens têm contato com tecnologias cada vez mais cedo, inserindo Smartphones, Tablets e Notebooks em suas atividades cotidianas. Segundo a Google, os Smartphones são a porta de entrada para Web (PIZZARO, 2018). Moran (2007) afirma que essas tecnologias funcionam como um apoio nas atividades escolares e são instrumentos fundamentais para a mudança na educação. Mas também destaca que existe a defasagem das escolas da Educação Básica e que este pensamento precisa ser mudado o quanto antes. Entende-se que as escolas brasileiras precisam investir e pensar novas formas pedagógicas para inserir a computação no cotidiano da escola. Ações nesse sentido já acontecem em outros países, como o Azerbaijão, Estônia, Reino Unido e EUA, que implantaram projetos de programação nas escolas, como identificado nos trabalhos de (BASHIROV et al., 2015; MATT, 2014; SAEZ-LOPEZ; ROMAN-GONZALEZ; AZQUEZ-CANO, 2016).

Lima, Vieira e Brandão (2019) afirmam que no Brasil o uso das tecnologias nas escolas ainda é superficial, principalmente na rede pública. Entretanto, algumas iniciativas de inserção da computação na Educação Básica vêm sendo adotadas. Como exemplo, a prefeitura da cidade de São Paulo/SP que inseriu no ano de 2018 aulas de programação e ética em internet (BALLOUSSIER; SALDAÑA, 2017). De acordo com Carvalho (2018), existe um projeto da FAPEMIG que pretende suprir as lacunas do ensino de programação no país. O público-alvo são alunos do Ensino Médio, principalmente das escolas públicas. Diante dessas iniciativas, é possível pensar na utilização de tecnologias de uma forma mais abrangente, como ensino de lógica de programação e introdução à robótica educacional (SOBRINHA et al., 2016).

Considera-se que esse tipo de aprendizagem ofertado ainda na escola pode auxiliar os alunos a desenvolverem um treinamento de raciocínio, o que facilitaria na tomada de decisão em diversas situações. Além disso, estimularia a criatividade dos alunos. Ostrower (1993) diz que a natureza criativa do homem se elabora no contexto cultural, onde criar corresponde a um formar, ou dar forma a alguma coisa, sejam quais forem os modos e os meios. Segundo Alencar (2007), a criatividade é uma característica que difere de indivíduo para indivíduo apenas em grau. Todo ser humano é naturalmente criativo e a extensão em que a criatividade se desenvolve depende largamente do ambiente. $O$ autor afirma ainda que a criatividade não é algo que acontece por acaso, podendo ser deliberadamente empregada, gerenciada, desenvolvida. Cabe à escola maximizar as oportunidades de expressão da criatividade nos processos de ensino e aprendizagem, dando mais oportunidades de construção criativa através das emoções e da sua expressão (ALENCAR, 2007; COSTA-LOBO et al., 2017).

A nova geração precisa de incentivos e ferramentas para que desenvolvam seu senso crítico e busque aprender não apenas em sala de aula. É preciso incentivar o aluno a ser criativo, 
mantendo-o interessado a buscar novas ferramentas e informações. Esse processo é necessário para a aquisição do conhecimento, que segundo Gavira (2003), é quando damos significado às informações recebidas. O autor acredita que simulação computacional seja uma ferramenta satisfatória para converter a informação em conhecimento. Kaminski e Boscarioli (2019) afirmam que o ensino de programação propicia o desenvolvimento de habilidades importantes no que se refere à formação de um cidadão crítico, atuante e participativo. Além disso, possibilita o trabalho interdisciplinar dos conteúdos curriculares. Morais et al. (2017) afirmam que é necessário o desenvolvimento de novas experiências em sala de aula para que educadores se aventurem a ensinar conteúdos a partir da programação.

Com o objetivo de levar o ensino de lógica de programação para alunos da Educação Básica, foi criado o projeto de extensão "Gamificação para o ensino de lógica de programação: uma abordagem lúdica aplicada em uma escola pública de ensino básico de Diamantina". O projeto foi executado na cidade de Diamantina, situada no Vale do Jequitinhonha, interior de Minas Gerais. Os monitores foram discentes do curso de graduação Interdisciplinar em Ciência e Tecnologia do Instituto de Ciência e Tecnologia da Universidade Federal dos Vales do Jequitinhonha e Mucuri - UFVJM. O curso foi ofertado em três escolas utilizando seus respectivos espaços físicos. Para apresentar a lógica de programação para os participantes, foram utilizadas as plataformas CODE (CODE.ORG, 2018) e MIT AppInventor (MIT, 2019). Essas plataformas oferecem um design de fácil entendimento para iniciantes, utilizando programação em blocos de forma lúdica.

Prezando pela indissociabilidade entre ensino, pesquisa e extensão, foi realizada uma pesquisa sobre os impactos do curso de extensão para os alunos participantes. Seguiu-se recomendações do Comitê de Ética em Pesquisa da instituição para que todo o processo se baseasse em padrões éticos. Foi analisado, a partir da percepção dos participantes, se o ensino de programação nas escolas de Ensino Básico pode contribuir para a formação dos alunos. Além disso, foi observado se houve motivação e satisfação dos participantes. Outro ponto analisado foi se o projeto proporcionou a base inicial para os alunos desenvolverem aplicativos, bem como o interesse em buscar novos conhecimentos relacionados ao tema. Por fim, foi analisado se o aluno se interessou em seguir uma carreira profissional na área de exatas ou computação após o curso.

O restante deste trabalho está dividido da seguinte forma: as Seções 2 e 3 apresentam as plataformas utilizadas para as aulas com os alunos; na Seção 4 são descritos os procedimentos e métodos usados na pesquisa; a Seção 5 apresenta os resultados encontrados e discussões relacionadas com trabalhos semelhantes; por fim, a Seção 6 expõe as conclusões do artigo.

\section{Plataforma CODE.ORG $®$}

CODE.ORG $®$ é um projeto lançado para promover o ensino de programação nas escolas (CODE.ORG $®$, 2018). O projeto disponibiliza uma série de cursos e ferramentas para o ensino de computação para jovens. A plataforma oferece uma ferramenta interativa onde o 
programador move um personagem na tela para concluir algum objetivo específico. Na Figura 1, por exemplo, o personagem precisa trilhar um labirinto para chegar ao girassol. Na tela de Blocos do lado direito, observa-se a codificação para que a tarefa seja alcançada com sucesso. Para isso o personagem precisa dar dois passos à frente, virar à esquerda, dar mais dois passos à frente, virar à direita e repetir todos os passos novamente. Para concluir a tarefa, o estudante deve montar os blocos conforme ilustrado na Figura 1.

Figura 1 - Tela do CODE.ORG®.

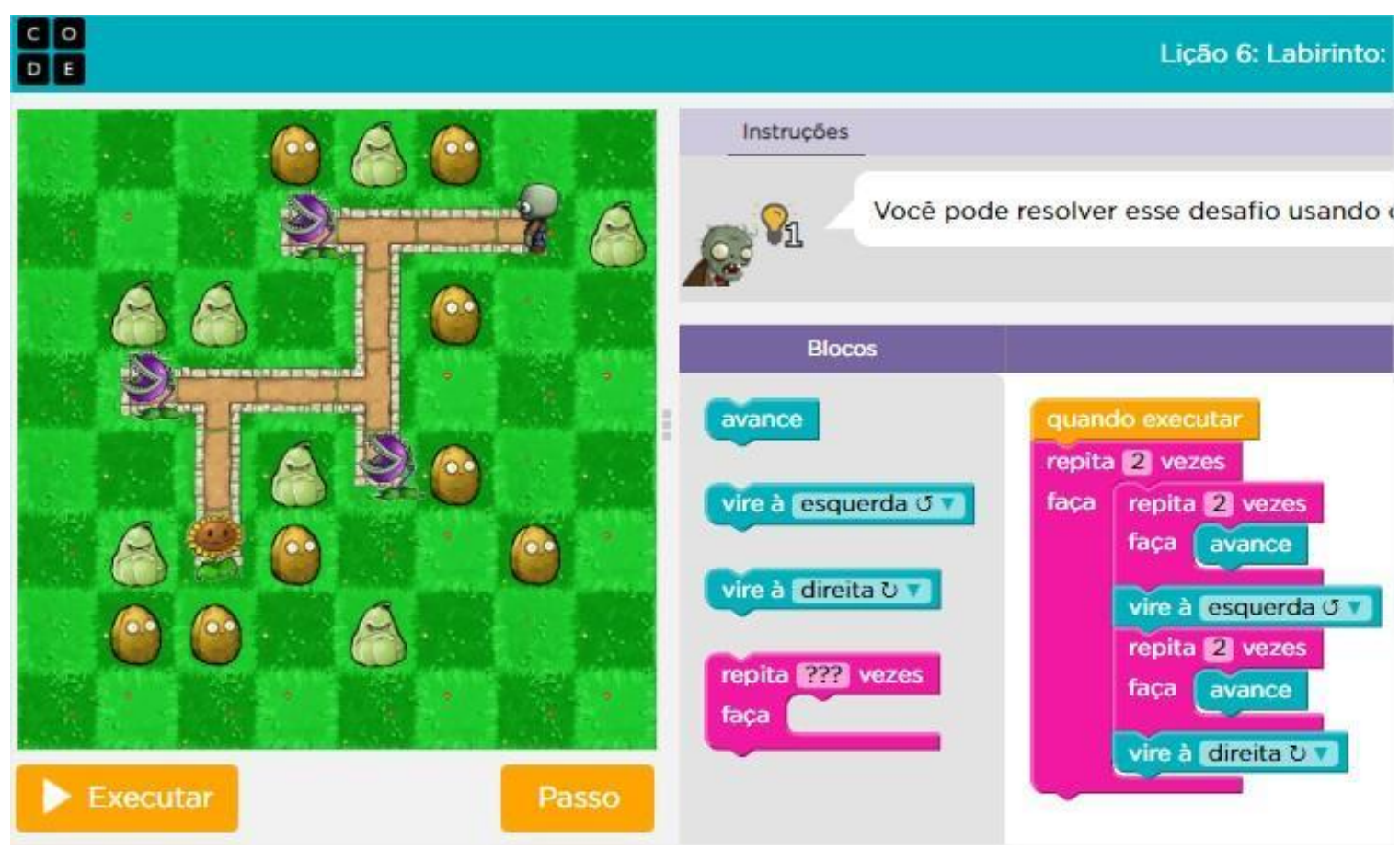

Fonte: Autores utilizando a plataforma CODE.ORG, 2018.

Morais et al. (2017) chama a atenção para a necessidade de pessoas com conhecimento em

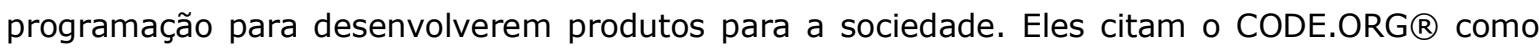
um dos programas que influenciam nessa demanda. Os autores ainda expõem a grande demanda por profissionais da área e a escassez de programadores no mercado brasileiro. Kurihara et al. (2015) defendem que a programação baseada em blocos visuais é útil para vários usuários, como programadores novatos, pois oferece operações fáceis e melhora a legibilidade dos programas.

Good e Howland (2017) afirmam que os jovens se sentem motivados a criar jogos que sejam semelhantes ao estilo e à aparência dos jogos comerciais que são acostumados a jogar. Eles estão dispostos a dedicar tempo e esforço consideráveis para aprenderem a desenvolvê-los.

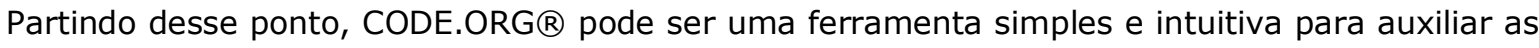
crianças com pouca idade a iniciarem na programação. Para Matt (2014), o trabalho de 
desenvolver o raciocínio lógico deveria iniciar na Educação Básica e de maneira adequada, como tem sido feito em alguns países, de maneira lúdica e gradativa. Cafiero, Pinheiro, e Gomide (2018) afirmam que a melhor maneira de apresentar programação para iniciantes é com ferramentas de linguagens de blocos, pois facilitam a interação e entendimento dos códigos.

\section{Plataforma MIT AppInventor}

Segundo Finizola et al. (2014), o MIT AppInventor é uma plataforma de programação orientada a design para a criação de aplicações para a plataforma Android (smartphones e tablets), desenvolvida pelo MIT - Massachusetts Institute of Technology em parceria com a Google. Júnior e Boniati (2015) argumentam que essa ferramenta não faz uso de programação tradicional. Ela permite uma programação de aplicativos utilizando blocos de encaixe, facilitando o aprendizado dos iniciantes em programação. Dessa forma, permite que programadores desenvolvam aplicações utilizando apenas sua lógica. Maciel, Mendes e Marques (2018) utilizaram a ferramenta e obtiveram um bom desenvolvimento dos alunos quanto à criação de seus próprios aplicativos focados em acessibilidade.

MIT AppInventor é uma plataforma online onde os alunos se cadastram e desenvolvem seus projetos. À medida que um aplicativo é criado, o usuário pode fazer uma conexão entre a plataforma e seu dispositivo móvel, assim ele consegue executar testes no aplicativo e verificar se está conforme o esperado. Na Figura 2 é ilustrada a tela de codificação do MIT AppInventor mostrando parte de funções de um aplicativo.

Figura 2 - Tela do MIT AppInventor.
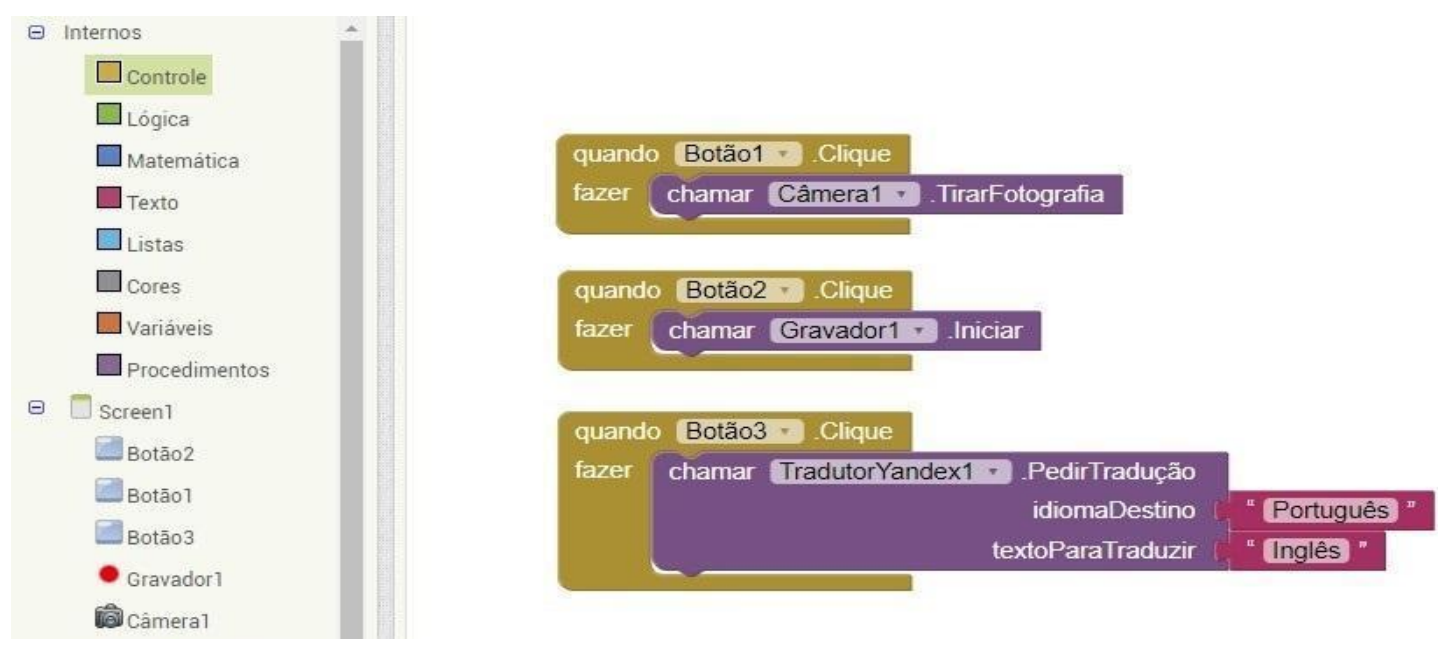

Fonte: Autores utilizando a plataforma MIT, 2019.

\section{Procedimentos e métodos}

Para a execução do projeto de extensão, foram realizados convites a algumas escolas públicas da cidade de Diamantina/MG. De acordo com a aceitação das escolas, foram definidas 
as datas dos cursos em cada uma delas. Três escolas se interessaram pelo projeto e se prontificaram a ceder seus espaços físicos para as aulas e a selecionarem os alunos participantes na faixa etária entre 12 e 16 anos. As escolas participantes foram: Escola Estadual Professora Ayna Torres; Escola Estadual Professor Gabriel Mandacarú; e Colégio Tiradentes da PMMG.

Para executar o projeto, foi necessário um laboratório de informática com acesso à internet e navegador web instalado. O número de alunos selecionados foi definido de acordo com a estrutura de laboratório de informática disponível nas escolas. O Quadro 1 sintetiza as informações dos cursos em cada escola participante.

Quadro 1 - Informações gerais do cursos.

\begin{tabular}{llll}
\hline & E.E. Ayna Torres & E.E. Gabriel Mandacaru & C. Tiradentes \\
\hline Turno & $\begin{array}{l}\text { Após as aulas da escola } \\
\text { (após às 17:45) }\end{array}$ & $\begin{array}{l}\text { Intercalado com as aulas } \\
\text { (período da tarde) }\end{array}$ & $\begin{array}{l}\text { Contraturno } \\
\text { (período da manhã) }\end{array}$ \\
Carga horária semanal & 2 horas & 3 horas & 2 horas \\
Encontros semanais & 2 & 2 & 1 \\
Carga horária total & Aproximadamente 25 horas & Aproximadamente 30 horas & Aproximadamente 12 horas \\
Duração total & 2 meses & 2,5 meses & 1,5 mês \\
Evasão total & $32 \%$ & $30 \%$ & $86 \%$ \\
\hline
\end{tabular}

Fonte: Autores.

As duas primeiras turmas do projeto foram ofertadas na Escola Estadual Professora Ayna Torres. A duração das aulas foi de uma hora, duas vezes por semana, após as aulas normais. No total, foram selecionados 19 alunos, dos quais 13 concluíram o curso. A segunda instituição a participar do projeto foi a Escola Estadual Professor Gabriel Mandacarú. Foram contemplados alunos matriculados na modalidade Telessala que é um projeto do Governo do Estado de Minas Gerais que utiliza recursos tecnológicos presentes em algumas escolas (MINAS GERAIS, 2016). De acordo com Telecurso (2019), na Telessala os estudantes assistem às teleaulas junto com um professor formado na metodologia. A turma totalizava 17 alunos frequentes. Inicialmente, 12 alunos se interessaram por participar do curso. A terceira instituição a participar do projeto foi o Colégio Tiradentes da Polícia Militar onde o curso foi ofertado no contraturno. Com isso o esperado era que o número de interessados fosse mais baixo que nas outras instituições. Isso porque a maioria dos alunos depende dos pais para se deslocar até a escola. Além disso, o curso foi ofertado na parte da manhã e os alunos teriam que voltar para casa antes das aulas da tarde. Para iniciar o curso, foi realizado o convite para uma turma de 40 alunos. Destes, apenas sete compareceram e participaram do curso.

Os monitores do curso foram alunos de graduação da UFVJM. Durante o tempo utilizado para os cursos, os participantes ficavam sob responsabilidade dos monitores além do pesquisador que acompanhava as atividades para fazer a análise de desempenho. 
A proposta do curso foi apresentar os conceitos básicos de lógica de programação em blocos

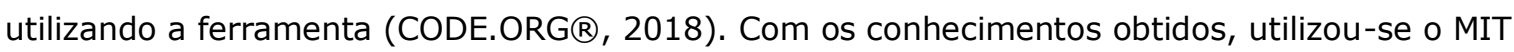
AppInventor para criar aplicativos Android. A ideia foi mostrar como a programação em blocos pode ser utilizada para a criação de aplicativos reais. A duração total prevista para o curso foi de dois meses, sendo um mês para o CODE.ORG® e um mês para o MIT AppInventor.

Para a introdução dos conceitos da programação em blocos, utilizou-se o "Curso 2" da plataforma CODE.ORGß. Esse curso é voltado para crianças alfabetizadas. A conclusão dessa atividade foi obrigatória para seguirem para o desenvolvimento de aplicativos no MIT AppInventor. Nessa nova etapa, os participantes tiveram a liberdade de desenvolver o que Ihes interessavam. Os monitores os ajudaram a pensar em boas ideias e mostrar a melhor maneira de desenvolver. Dentre os aplicativos desenvolvidos pelos alunos, destacam-se: calculadoras básicas, fala Android, desenho livre, compartilhamento de fotos e jogos de aviões em 2D. As "calculadoras básicas" desenvolvidas permitiam fazer operações aritméticas simples. Aplicativos de "fala Android" tinham o objetivo de falar frases à medida que o usuário praticava alguma movimentação ou ação no seu dispositivo. O "desenho livre" possibilitou ao usuário esboçar qualquer tipo de ilustração. O "compartilhamento de fotos" utilizou a câmera local para tirar fotos e compartilhar com outras pessoas. Aplicativos de jogos de aviões tiveram a função de um avião desviar de obstáculos. Por mais que sejam aplicativos simples, os alunos conseguiram desenvolver o que projetaram e conseguiram compilar o aplicativo em seu celular. Acredita-se que com mais tempo disponível, os aplicativos ganhariam mais funções e melhorias.

A pesquisa seguiu todas as normas exigidas pelo Comitê de Ética e Pesquisa da instituição proponente e é identificada com o número CAAE 90865418.9.0000.5108. Como a população estudada foi formada por adolescentes, o Termo de Consentimento Livre e Esclarecido (TCLE) e o Termo de Assentimento de Menor foram coletados pelo pesquisador junto aos pais ou responsáveis legais dos participantes. A pesquisa é classificada como estudo de campo e na análise dos dados foi utilizada a abordagem quanti-qualitativa. De acordo com Gil (2010), o estudo de campo é um tipo de pesquisa focado em uma comunidade. Ela se desenvolve por meio de observação direta das atividades do grupo, além de questionários para colher os dados. A decisão em utilizar a abordagem quantitativa concomitante à qualitativa se sustentou pela utilização de dois instrumentos de pesquisa diferentes. $O$ primeiro se caracteriza qualitativamente, sendo uma observação direta feita pelo pesquisador junto à população estudada. A segunda técnica é a análise de respostas dos questionários, que são instrumentos padronizados de coleta e que conduzem resultados de natureza quantitativa. Segundo Freitas, Charbel e Jabour (2011), essa combinação metodológica é uma forma robusta de se produzir conhecimento, pois não são excludentes, além de uma superar as limitações da outra. A abordagem quanti-qualitativa levou a um entendimento mais elaborado sobre os resultados, buscando relacionar o comportamento em sala com as respostas obtidas nos questionários.

Foram elaborados dois questionários. O primeiro foi respondido antes das aulas acontecerem. O segundo foi aplicado ao final do curso. No Quadro 2 estão listadas perguntas aplicadas no primeiro questionário. No Quadro 3 são apresentadas as perguntas do segundo questionário. 
Quadro 2 - Perguntas aplicadas antes do curso.

\begin{tabular}{lll}
\hline Perguntas & & Opções de respostas \\
\hline Pergunta 1 & $\begin{array}{l}\text { Você tem algum conhecimento de programação ou criação de } \\
\text { aplicativos? }\end{array}$ & Sim; Não; Prefiro não responder \\
Pergunta 2 & $\begin{array}{l}\text { Você sente falta de uma disciplina que ensine computação na } \\
\text { escola? }\end{array}$ & Sim; Não; Prefiro não responder \\
Pergunta 3 & $\begin{array}{l}\text { Você já havia pensado em fazer curso técnico ou superior nas } \\
\text { áreas de exatas, computação ou engenharias? }\end{array}$ & Simão; Prefiro não responder \\
\hline
\end{tabular}

Fonte: Autores.

Quadro 3 - Perguntas aplicadas após o curso.

\begin{tabular}{|c|c|c|}
\hline Pergunta 1 & Você se sentiu motivado no decorrer das aulas? & Sim; Não; Prefiro não responder \\
\hline Pergunta 2 & $\begin{array}{l}\text { Você acha que seu desempenho escolar melhorou após a } \\
\text { participação no curso? }\end{array}$ & $\begin{array}{l}\text { Melhorou; Piorou; Permaneceu igual; } \\
\text { Prefiro não responder }\end{array}$ \\
\hline Pergunta 4 & $\begin{array}{l}\text { Antes do curso você já tinha algum conhecimento de } \\
\text { programação ou criação de aplicativos? }\end{array}$ & $\begin{array}{l}\text { Bastante; Pouco; Nenhum; Prefiro não } \\
\text { responder }\end{array}$ \\
\hline Pergunta 5 & $\begin{array}{l}\text { Você já havia pensado em fazer curso técnico ou superior na } \\
\text { área de exatas, antes de participar do curso? }\end{array}$ & Sim; Não; Prefiro não responder \\
\hline Pergunta 7 & $\begin{array}{l}\text { No decorrer do curso, você desenvolvia as atividades em casa } \\
\text { ou apenas no horário correspondente às aulas? }\end{array}$ & $\begin{array}{l}\text { Em casa e na escola; Apenas na } \\
\text { escola; Prefiro não responder }\end{array}$ \\
\hline Pergunta 8 & $\begin{array}{l}\text { Você acredita que obteve conhecimentos para desenvolver } \\
\text { um aplicativo? }\end{array}$ & $\begin{array}{l}\text { Sim, bastante; Sim, um pouco; Não, } \\
\text { nenhum; Prefiro não responder }\end{array}$ \\
\hline Pergunta 9 & $\begin{array}{l}\text { Após concluir o curso, você continua interessado em } \\
\text { desenvolver aplicativos? }\end{array}$ & Sim; Não; Prefiro não responder \\
\hline Pergunta 10 & Você ficou satisfeito com o curso? & Sim; Não; Prefiro não responder \\
\hline
\end{tabular}

Fonte: Autores.

As questões 1 do Quadro 2 e 4 do Quadro 3, buscam o mesmo objetivo que é saber se antes do curso o aluno tinha conhecimento de programação. O motivo para a aplicação da mesma pergunta nos dois momentos se justifica pois a primeira turma do curso de extensão se iniciou antes de se decidir realizar uma pesquisa. Portanto, nessa turma não foi aplicado o primeiro questionário. Como havia a necessidade de saber se esses alunos tinham conhecimento de programação antes do curso, optou-se por manter a pergunta no questionário pós-curso. 


\section{Resultados}

Nesta seção será apresentado o relato das experiências nos cursos ofertados para as três escolas parceiras. Foram realizadas as análises das aulas e questionários aplicados aos alunos participantes do projeto. Por fim, é elaborada uma análise relacionando os resultados obtidos. 0 primeiro curso foi ofertado na Escola Estadual Professora Ayna Torres, o segundo curso na Escola Estadual Professor Gabriel Mandacarú e o último no Colégio Tiradentes da PMMG.

\subsection{Andamento das aulas}

Durante os cursos realizados na Escola Estadual Professora Ayna Torres, foi possível observar um bom desempenho de todos os concluintes. Não houve grandes problemas técnicos e nem de comportamento dos participantes. Com isso, os prazos propostos foram cumpridos. O maior problema identificado foi a evasão, que chegou a aproximadamente $32 \%$ somadas as duas turmas. Mesmo com o curso sendo realizado após o horário das aulas, notou-se que os alunos que chegaram até o final se mantiveram bastante motivados em participar de uma atividade fora da rotina escolar. Por parte da equipe do projeto houve uma grande satisfação com o desempenho dos alunos concluintes. Esse fator foi de grande influência para levar o projeto para outras escolas.

Na Escola Estadual Professor Gabriel Mandacarú o perfil dos alunos foi diferente se comparado ao da primeira escola, sendo que a turma foi composta por alunos com distorção idade/série. Nessa turma, houve maior índice de desinteresse pela atividade. No decorrer das aulas foram observados alunos sem foco e utilizando o computador para acessar as redes sociais, sites de compras ou vídeos. Além dessa dificuldade, a equipe do projeto se deparou com problemas técnicos como computadores defeituosos e falta de internet em alguns deles. Esse tipo de problema, principalmente dificuldade de acesso à internet são comuns e listados em outros trabalhos (FIORI; ROCHA; MARQUES, 2019; KAMINSKI; BOSCARIOLI, 2019). A soma de problemas técnicos com a falta de interesse de alguns participantes causou desmotivação na equipe de monitores. Foi preciso tomar uma decisão para que o curso se desenvolvesse com mais agilidade para a etapa final. Após quase dois meses apenas com a plataforma CODE.ORG $®$, identificou-se quais alunos concluíram essa etapa ou estavam em conclusão, para que apenas eles dessem continuidade ao curso. Sendo assim, foram selecionados sete alunos dos 12 iniciantes para trabalhar com o MIT AppInventor. Assim, considera-se um índice de evasão de quase $30 \%$. Após a seleção, os participantes escolhidos receberam a segunda parte do curso dentro do prazo estabelecido.

No Colégio Tiradentes da Polícia Militar não houve participantes dispersos ou fazendo outras tarefas durante as aulas. Todos conseguiram fazer as tarefas propostas na plataforma CODE.ORG $®$. Em apenas cinco horas de aulas com CODE.ORG $®$, eles chegaram ao nível desejado para trabalharem com o MIT AppInventor. Infelizmente, a segunda etapa não obteve o andamento desejado. Depois do feriado de carnaval, houve 15 dias de avaliações no colégio. 
Nesse período o curso ficou paralisado e no final do mês de março quando seria dada continuidade no curso, apenas um participante frequentou as aulas. Diversos convites foram feitos para remarcação de horários, mas mesmo assim não foi possível a conclusão do curso pelo restante da turma. Acredita-se que o fato do curso ter sido interrompido durante três semanas desmotivou os alunos participantes a concluírem o curso. Dessa forma, considerou-se que a evasão foi de aproximadamente $86 \%$. Com isso, utilizou-se apenas uma amostra desta turma para fazer parte dos resultados dos questionários desta pesquisa. Quanto ao restante da turma, aproveitou-se apenas os resultados da primeira etapa do curso, como parte da análise qualitativa.

\subsection{Análises dos Questionários}

A partir das respostas dos questionários aplicados, foi possível identificar pontos positivos e negativos do projeto de extensão. A seguir é feita uma análise dos resultados.

As Perguntas no 2 e no 3 do Quadro 3 investigam se o ensino de programação nas escolas de ensino básico pode contribuir para a formação dos alunos. Para isso foi analisada a percepção dos participantes em relação ao seu desempenho e frequência escolar. De todos os participantes, 17 responderam às perguntas. Desses, 59\% responderam que seu desempenho escolar melhorou após o curso, e 53\% responderam que a frequência escolar aumentou.

Para identificar se houve motivação e satisfação dos participantes do projeto de extensão quanto ao acesso a uma atividade interdisciplinar em seu ambiente escolar, aplicou-se as Perguntas no 2 do Quadro 2, no 1 e no 10 do Quadro 3. Os participantes responderam sobre a motivação nas aulas e de acordo com as 16 respostas, $100 \%$ delas mostram que o curso proporcionou motivação, pois eles tiveram contato com uma atividade interdisciplinar em sua instituição. Quanto à satisfação no curso, das 17 respostas apenas um participante disse que não ficou satisfeito com o curso. Isso mostra a importância de tarefas inovadoras na vida acadêmica de crianças e adolescentes. As respostas à Pergunta no 2 do Quadro 2 já antecipava esse resultado, pois $100 \%$ dos que responderam, afirmaram que gostariam de disciplinas com conteúdos inovadores envolvendo computação na escola.

Para observar a capacidade dos alunos em desenvolverem seus próprios aplicativos foram aplicadas as Perguntas no 1 do Quadro 2, no 4, no 7 e no 8 do Quadro 3. Os resultados mostram que a maioria não tinha contato com programação anteriormente. Quanto ao desenvolvimento das tarefas, 59\% dos participantes afirmaram que desenvolviam as tarefas em casa e na escola. Os outros $41 \%$ responderam que desenvolviam apenas nos horários das aulas do curso de programação. Sobre a opinião dos participantes se eles realmente adquiriram conhecimentos para desenvolver um aplicativo para dispositivo móvel utilizando MIT AppInventor, $100 \%$ dos participantes afirmaram que sim. Porém, $47,1 \%$ responderam que "Sim, tiveram bastante conhecimento" e ou outros $52,9 \%$ disseram que "Sim, tiveram pouco conhecimento" para desenvolverem. Isso os deixou interessados em buscar novos conhecimentos relacionados ao 
tema. Quanto à Pergunta no 9 do Quadro 3, 76\% responderam que continuam interessados em desenvolverem aplicativos.

As Perguntas no 3 do Quadro 2, no 5 e n० 6 do Quadro 3 tinham o objetivo de verificar se através do curso o aluno obteve interesse em seguir uma carreira profissional na área de exatas ou computação. Uma parcela significativa informou que antes do curso nunca tinha pensado em fazer um curso técnico ou superior na área de exatas, chegando a aproximadamente $47 \%$ das respostas. Após o curso, esse pensamento mudou. Constatou-se que $94 \%$ dos participantes responderam que pensam em fazer curso na área de exatas, mais precisamente computação.

\section{Discussões}

Nesta pesquisa foi observado que o ensino de programação nas escolas de ensino básico pode apresentar fatores que venham a contribuir para a formação dos alunos. Maciel, Mendes e Marques (2018) observaram que todos os alunos participantes do projeto deles indicaram melhora no desenvolvimento escolar inclusive com boa frequência nas aulas. Com isso, é possível supor que atividades que exigem pensamento lógico envolvendo tecnologia e jogos lúdicos podem contribuir para a frequência e o desempenho escolar dos alunos que se interessam pelo tema. Além disso, acredita-se que esse tipo de projeto estimula o desenvolvimento de raciocínio, criatividade, resolução de problemas, que poderão beneficiar outras atividades do cotidiano dos participantes. Portanto, entende-se que o projeto de extensão foi capaz de levar benefícios para a formação dos envolvidos.

Quanto à motivação e satisfação constatadas no projeto, resultados similares foram mencionados por outros autores (AMARAL; SILVA; PANTALEÃO, 2015; GENNARI et al., 2017; HAMARI et al., 2016). Motivação e satisfação são importantes em qualquer atividade de nosso dia-a-dia. São sentimentos que agem positivamente no indivíduo, incentivando-o a continuar aprendendo.

Sobre a capacidade de desenvolver aplicativos adquirida pelos participantes, os resultados corroboram os apresentados por Maciel, Mendes e Marques (2018), quando eles confirmam a facilidade que alunos tiveram em desenvolver aplicativos utilizando a plataforma MIT AppInventor. Analisando as respostas dos questionários desta pesquisa, aproximadamente $85 \%$ dos participantes não tinham conhecimentos sobre programação de computadores. Entretanto, ao final todos afirmaram que conseguiram obter ao menos uma base para programar aplicativos simples. Isso mostra que o objetivo de ajudar o participante a descobrir o percurso para desenvolver aplicativos foi atingido. Além disso, ficou constatado o interesse dos alunos na tarefa, pois quase $60 \%$ disseram que faziam tarefas do curso em casa. Esse resultado reafirma a motivação e satisfação dos participantes quanto ao curso. A maioria dos concluintes conseguiu desenvolver seu aplicativo, mesmo que o aplicativo desenvolvido resolvesse um problema simples. No trabalho de Perlin, Macedo e Silveira (2019), concluiu-se que os alunos compreenderam noções de linguagens de programação utilizando ferramentas lúdicas. Com isso pode-se afirmar que cursos de programação para iniciantes, baseados em programação em 
blocos, auxiliam crianças e adolescentes a criarem aplicativos.

Assim, espera-se que os participantes busquem novas ferramentas de desenvolvimento. Alguns trabalhos apresentaram resultados semelhantes, como França, Silva e Amaral (2012) que afirmam que os alunos de sua pesquisa relataram o aumento do interesse pela área e pela busca de novos conhecimentos. Segundo Scaico et al. (2012), os participantes se sentem motivados a continuarem aprendendo outras linguagens de programação. Os autores dizem que o seu projeto representa uma mudança na cultura da escola e o fortalecimento da formação dos estudantes de computação, que percebem o projeto como um espaço fértil e promissor para a geração de novos conhecimentos.

Nesta pesquisa, destaca-se o aumento do interesse dos participantes em cursarem computação no futuro. Esse resultado demonstra que o curso de extensão foi capaz de apresentar novas possibilidades profissionais para os participantes. Aqueles que nunca pensaram em cursar computação já cogitam como uma oportunidade real após receberem o curso básico de programação. Em um trabalho similar, Scaico et al. (2012) disseram que provavelmente sem as informações que alunos receberam em seu curso de programação, não teriam interesse em computação e nunca cogitariam entrar em um curso superior na área.

Tanto Garlet, Bigolin e Silveira (2018) quanto Perlin, Macedo e Silveira (2019) acreditam que ações nesse sentido podem amenizar o elevado número de evasão em cursos na área de exatas, já que os alunos ingressarão com algum conhecimento sobre a lógica computacional. Esses autores defendem que o contato prematuro com programação pode influenciar positivamente nos cursos superiores de exatas, facilitando a vida acadêmica e com isso diminuindo a evasão.

Comparando os resultados de antes e depois do curso de extensão, observa-se a evolução do interesse em cursar computação por parte dos participantes. Pode-se afirmar que houve um acréscimo no interesse pela área após terem um contato básico com a lógica de programação em sua escola. Perlin, Macedo e Silveira (2019) encontraram o mesmo resultado em um estudo de caso por eles desenvolvido. Os autores aplicaram o ensino de programação com ferramenta lúdica para jovens de Ensino Médio e constataram o interesse dos participantes em seguirem uma graduação na área.

Relacionando com o trabalho de Scaico et al. (2012), a influência se fortalece não só com a aprendizagem do conteúdo, mas também com as informações obtidas, onde alunos percebem que as atividades existentes na computação são diferentes do que imaginavam. Resultados similares foram encontrados também em outras referências utilizadas nesta pesquisa (AMARAL; SILVA; PANTALEÃO, 2015; FRANÇA; SILVA; AMARAL, 2012). Esses autores afirmam que o conteúdo de lógica computacional para jovens é uma boa forma de recrutá-los para o ensino superior. Pode-se entender que a maioria destes jovens envolvidos nos projetos, desenvolve o interesse pela área.

O destaque negativo encontrado no projeto foi o índice de evasão dos participantes que chegaram a aproximadamente $32 \%$ na primeira escola, $30 \%$ na segunda e $86 \%$ na terceira. Resultados similares foram identificados em outra referência cujo trabalho foi semelhante a este (MACIEL; MENDES; MARQUES, 2018). Observou-se alto índice de desinteresse dos convidados, 
o que pode estar relacionado às ideias apresentadas por Geraldes (2014), que observou que alguns especialistas da área de computação e profissionais da educação defendem que programar não é para todos. $O$ autor diz ainda que alguns educadores acreditam que o ensino de programação prejudica a infância, por retirar a oportunidade de socialização com outras crianças através das brincadeiras e jogos próprios dessa fase.

Levando em consideração esse pensamento de alguns educadores, pode-se relacionar com a falta de interesse de outras escolas convidadas a participarem do projeto de extensão. Além disso, nas escolas parceiras a maioria dos convidados não ingressou nos cursos, sendo que, entre os que ingressaram, houve alto índice de evasão. O melhor resultado balanceando menor índice de evasão e bom desempenho dos alunos foi na primeira escola, onde o curso foi ofertado logo após as aulas normais. Os alunos saíam da sala de aula e se deslocavam para o laboratório de informática, com isso eles não se dispersavam e conseguiram um bom desempenho, mantendo boa frequência no curso.

O projeto de extensão teve resultados positivos, sendo que o de maior impacto para a pesquisa foi o interesse em cursar programação no futuro. Apenas um dos concluintes respondeu que não se interessou em cursar computação futuramente, mesmo depois de participar no curso na escola. Projetos deste tipo são capazes de ajudar os participantes a entenderem que novos horizontes podem ser explorados. Métodos inovadores na educação necessitam de incentivo e atitudes voltadas a apresentá-los a quem pode se beneficiar. A iniciativa foi válida, mesmo que para um pequeno público, e observou-se que o projeto incentivou novas formas de pensar, de se expressar e tomar decisão.

\section{Conclusões}

O projeto de extensão cumpriu seu papel, incentivando uma diferente forma de se expressar utilizando ferramentas até então desconhecidas para os participantes. Alguns deles não tinham equipamentos computacionais em casa. Por isso a escola teve papel fundamental nesta nova oportunidade de aprendizado. Pode-se entender que é preciso estimular projetos que visem a utilizar de forma produtiva os equipamentos existentes nas escolas.

O ensino de lógica de programação para crianças beneficia o desenvolvimento do processo de aprendizagem, como o raciocínio lógico e a tomada de decisão, auxiliando na formação de ideias e resolução de problemas. Apesar da deficiência no quantitativo de projetos que levem esse conteúdo para as escolas brasileiras, vários são os benefícios da implantação de cursos ou oficinas de programação para iniciantes. Ofertou-se um conteúdo interdisciplinar relacionado ao lúdico através de ferramentas que facilitam o ensino da lógica computacional, utilizando linguagem em blocos. O método apresentou uma forma didática e simples de representar algoritmos. As plataformas CODE.ORG® e MIT AppInventor utilizadas nas aulas se mostraram eficazes, oferecendo à iniciantes uma forma fácil de programar.

Apesar do alto índice de evasão, o projeto alcançou o que se destinou a fazer. Possibilitou aos alunos das escolas participantes a terem o primeiro contato com a lógica de programação. Os 
resultados apresentados indicam o alto índice de motivação e satisfação dos participantes concluintes sobre o novo conteúdo aprendido. O projeto permitiu aos envolvidos a obterem um mínimo de conhecimento para desenvolverem aplicativos para dispositivos móveis. Outro fator relevante foi o interesse de alguns participantes em continuar buscando novos conhecimentos na área e cursar computação no futuro.

Para que o ensino de programação ocupe espaço nas escolas em uma abrangência nacional, iniciativas precisam partir de políticas públicas, assim como em outros países citados neste trabalho. É preciso que os governos invistam em conteúdos tecnológicos para explorar o potencial criativo que as gerações de hoje possuem.

\section{Agradecimentos}

Os autores agradecem à Pró-reitoria de Extensão e Cultura (PROEXC) da UFVJM e às escolas parceiras: Escola Estadual Professora Ayna Torres; Escola Estadual Professor Gabriel Mandacarú; e Colégio Tiradentes da PMMG. 


\section{Referências}

ALENCAR, E. M. L. S. de. Criatividade no contexto educacional: três décadas de pesquisa. Psicologia: Teoria e Pesquisa, Brasília, v. 23, n. spe, p. 45-49, 2007 . Disponível em: <http://www.scielo.br/scielo.php?script=sci_arttext\&pid=S0102-37722007000500008\&lng=en\&nrm =iso >. Acesso em: 12 Jun. 2020. https://doi.org/10.1590/S0102-37722007000500008.

AMARAL, L.; SILVA, G. B. e; PANTALEÃO, E. Plataforma Robocode como Ferramenta Lúdica de Ensino de Programação de Computadores - Pesquisa e Extensão Universitária em Escolas Públicas de Minas Gerais. In Anais do XXVI Simpósio Brasileiro de Informática na Educação (SBIE 2015), Maceió, Brasil, páginas 200208, v. 1, 2015.

BALLOUSSIER, A. V.; SALDAÑA, P. Rede paulistana terá já em 2018 aulas de programação e de ética na internet. São Paulo, 25 set. 2017. Disponível em: <http://www1.folha.uol.com.br/educacao/2017/07/1904059-rede-paulistana-tera-em-2018-aula-deprogramacao-e-etica-na-internet.shtml>. Acesso em: 2 maio. 2018.

BASHIROV, N. et al. Computer Assisted Training on Mathematics Lesson for the 6 th Grade Students on Azerbaijan Middle Schools. Procedia - Social and Behavioral Sciences, v. 176, p. 616-620, 2015. Disponível em: <https://www.sciencedirect.com/science/article/pii/S1877042815005558>. Acesso em: 12 dez. 2017.

CAFIERO, C.; PINHEIRO, J. V.; GOMIDE, J. Avaliação das Ferramentas Utilizadas em um Curso de Programação para Crianças: Percepções dos Alunos e seus Instrutores. In VII CBIE -Anais do XXIV Workshop de Informática na Escola (WIE 2018), v. 24, p. 51, 2018.

CARVALHO, R. Fapemig desenvolve plataforma gratuita de ensino de programação. 11 maio. 2018. Disponível em: <http://www.simi.org.br/noticia/fapemig-desenvolve-plataforma-gratuita-de-ensino-deprogramaçao.html>. Acesso em: 15 maio. 2018.

CODE.ORG. Code. 2018. Disponível em: <https://code.org>. Acesso em: 3 out. 2018.

COSTA-LOBO, C., CAMPINA, A., e MENEZES, J. (2017). Criatividade nas realidades educativas: considerações teoréticas. Revista Diálogos Possíveis, 1, 2 - 23. Acesso em: 11 Jun. 2020.

FINIZOLA, A. B. et al. O ensino de Programação para dispositivos móveis utilizando o MIT-App Inventor com alunos do ensino Médio. In Anais do XX Workshop de Informática na Escola (WIE 2014), v. 20, no. 1, Cbie, p. $337,2014$.

FIORI, M.; ROCHA, M.; MARQUES, A. Uma experiência de aprendizagem de lógica de programação com code.org no ensino médio: uma análise por gênero sobre a percepção dos estudantes. In Anais do XIII Women in Information Technology. SBC, 2019. p.124-128.

FRANÇA, R. S. De; SILVA, W. C. Da; AMARAL, H. J. C. Do. Ensino de ciência da computação na educação básica: Experiências, desafios e possibilidades. In Anais do XXXII Congresso da Sociedade Brasileira de Computação e XX Workshop de Educação em Informática, v. 4, 2012. Disponível em: <http://www.lbd.dcc.ufmg.br/colecoes/wei/2012/0011.pdf>

FREITAS, W. R. S.; CHARBEL, E.; JABBouR, J. C. Utilizando Estudos de Caso(s) como Estratégia de Pesquisa Qualitativa: Boas Práticas e Sugestões. Estudo \& debate, Lajeado , v. 18, n. 2, p. 7-22, 2011.

GARLET, D.; BIGOLIN, N. M.; SILVEIRA, S. R. Ensino de Programação de Computadores na Educação Básica: um estudo de caso. Resiget - Revista Eletrônica de Sistemas de Informação e Gestão Tecnológica. v. 9, n. 2, 2018. Disponível em: . Acesso em jun. 2019.

GAVIRA, M. O. Simulação computacional como uma ferramenta de aquisição de conhecimento. São Carlos. 146f. Dissertação (Mestrado em Engenharia) - Universidade de São Paulo, 2003.

GENNARI, R. et al. Children's emotions and quality of products in participatory game design. International Journal of Human Computer Studies, v. 101, n. Abril 2016, p. 45-61, 2017. Disponível em: <http://dx.doi.org/10.1016/j.ijhcs.2017.01.006> 
GERALDES, W. Programar É Bom Para As Crianças? Uma Visão Crítica Sobre O Ensino De Programação Nas Escolas. Texto Livre: Linguagem e Tecnologia, v. 7, n. 2, p. 105-117, 2014. Disponível em: <http://periodicos.letras.ufmg.br/index.php/textolivre/article/view/6143>

GIL, A. C. Como elaborar projetos de pesquisa. 4. ed. São Paulo: Atlas, 2010.

GOOD, J.; HOWLAND, K. Programming language, natural language? Supporting the diverse computational activities of novice programmers. Journal of Visual Languages and Computing, v. 39, p. 78-92, 2017. Disponível em: <https://www.sciencedirect.com/science/article/pii/S1045926X16301963>

HAMARI, J. et al. Challenging games help students learn: An empirical study on engagement, flow and immersion in game-based learning. Computers in Human Behavior, v. 54, p. 170-179, 2016. Disponível em: http://dx.doi.org/10.1016/j.chb.2015.07.045

JÚNIOR, R. P. M.; BONIATI, B. B. LogicBlocks : Uma Ferramenta para o Ensino de Lógica de Programação. Anais do EATI - Encontro Anual de Tecnologia da Informação e Semana Acadêmica de Tecnologia da Informação, p. 63-70, 2015. Disponível em: <http://eati.info/eati/2015/assets/anais/Longos/L7.pdf>

KAMINSKI, M. R.; BOSCARIOLI, C. Uso do Ambiente Code.org para Ensino de Programação no Ensino Fundamental I - Uma Experiência no Desafio Hora do Código. Revista ENCITEC, v. 9, n. 1, p. 63-76, 2019.

KURIHARA, A. et al. A programming environment for Visual block-based domain-specific languages. In: SCSE. 2015. p. 287-296. Disponível em: <http://dx.doi.org/10.1016/j.procs.2015.08.452>

LIMA, P; VIEIRA, P; BRANDÃO, L. Ensino de algoritmos, programação e matemática: panorama e estudo de caso para estudantes de escolas públicas brasileiras. In: Anais do Workshop de Informática na Escola. 2019. p. 697.

MACIEL, H.; MENDES, M.; MARQUES, A. B. Desenvolvimento de aplicativos móveis com AppInventor por alunos do ensino médio: relato de um projeto de extensão com foco em acessibilidade. In Anais do Workshop de Informática na Escola. 2018. p. 195

MATT, R. Programação vira disciplina em escolas infantis nos EUA. Califórnia 20 maio.2014. Disponível em: <http://www1.folha.uol.com.br/tec/2014/05/1456608-programacao-vira-disciplina-em-escolas-infantis-noseua.shtml>. Acesso em: 2 maio. 2018.

MINAS GERAIS. Resolução SEE № 2.957, DE 20 DE ABRIL DE 2016, Brasil. Acesso em: 24 maio. 2018.

MIT. MIT AppInventor. 2019. Massachusetts Institute of Technology. Disponível em: <https://appinventor.mit.edu/explore/>. Acesso em: 10 ago. 2019.

MORAIS, A. D. de et al. Educação Matemática \& Ciência da Computação na escola: aprender a programar fomenta a aprendizagem de matemática? Ciência \& Educação (Bauru), v. 23, n. 2, p. 455-473, 2017. Disponível em: <http://www.scielo.br/scielo.php?script=sci_arttext\&pid=S1516$73132017000200455 \&$ lng $=$ pt\&tlng=pt>

MORAN, J. M. A educação que desejamos: novos desafios e como chegar. Papirus Editora 2. ed. Campinas, SP, 2007.

OSTROWER, F. Criatividade e processos de criação. 9 ed. Petrópolis: Vozes, 1993. 187 p. Ilus.

PERLIN, R.; MACEDO, R. T.; SILVEIRA, S. R. Uma Abordagem Construtivista No Ensino De Algoritmos E Lógica De Programação Com O Auxílio De Uma Ferramenta Gamificada. E-Xacta, v. 12, n. 1, p. $29,2019$.

PIZZARO, L. Smartphone é porta de entrada para web segundo o Google. 01 maio. 2018. Disponível em: <https://www.otempo.com.br/interessa/tecnologia-e-games/smartphone-é-porta-de-entrada-para-websegundo-o-google-1.1606191>. Acesso em: 2 maio. 2018.

SAEZ-LOPEZ, J. E.-M.; ROMAN-GONZALEZ, M.; AZQUEZ-CANO, E. V. Visual programming languages integrated across the curriculum in elementary school: A two year case study using "Scratch " in five schools. Computers \& Education, v. 97, p. 129-141, 2016. 
SCAICO, P. D.; LIMA, A. A. de; SILVA, J. B. da; AZEVEDO, S.; PAIVA, L. F.; RAPOSO, E. H. S.; ALENCAR, Y.; MENDES, J. P. (2012) "Programação no Ensino Médio: Uma Abordagem de Ensino Orientado ao Design com Scratch". In Anais do XVIII WIE Rio de Janeiro, 26 a 30 de Novembro de 2012, pp.

SOBRINHA, V. H. P. S.; do NASCIMENTO, G. R. A; GOMES, R. D.; NETO, O. A. R. Plataforma para auxílio ao ensino de programação e robótica pedagógica. Revista Principia, v. 1, n. 31, p. 104-112, 2016.

TELECURSO. Telecurso. 2019. Disponível em: <http://www.telecurso.org.br/>. Acesso em: 6 jan. 2019.

Recebido em setembro de 2019.

Aprovado para publicação em outubro de 2020.

\section{Riann Martinelli Batista}

Programa de Pós-graduação em Educação e Diretoria de Educação a Distância - Universidade Federal dos Vales do Jequitinhonha e Mucuri - UFVJM, Brasil, riann.batista@ead.ufvjm.edu.br

\section{Euler Guimarães Horta}

Programa de Pós-graduação em Educação e Instituto de Ciência e Tecnologia - Universidade Federal dos Vales do Jequitinhonha e Mucuri - UFVJM, Brasil, euler.horta@ufvjm.edu.br

\section{Alexandre Ramos Fonseca}

Programa de Pós-graduação em Educação e Instituto de Ciência e Tecnologia - Universidade Federal dos Vales do Jequitinhonha e Mucuri - UFVJM, Brasil, arfonseca@ufvjm.edu.br 